DOI: $10.22559 /$ folklor.866

folklor/edebiyat, cilt:25, sayı:98, 2019/2

\title{
Millî Mücadele Dönemi Edebiyatında Halk Edebiyatı Çalışmaları Üzerine Dikkatler
}

\section{Cautions on Folk Literature Works in the Literature of the period of Natural Struggle}

\section{Hacer Gülşen ${ }^{1}$}

\begin{abstract}
Öz
1918 Mondros Mütarekesi’yle başlayan ve 1922 y1lı sonuna kadar devam eden Millî Mücadele döneminde Türk milleti kendisini bir ölüm kalım savaşının içinde bulur. İttifak milletleri ile katıldığımız I. Dünya savaşını kaybederiz. 30 Ekim 1918 tarihinde imzalan Mondros Mütarekesi ve 10 Ağustos 1920 tarihli Sevres Muâhedesi ile topraklarımız işgal edilir. Millî Mücadelemizin hazırlık safhasını 1919 ve 1920 seneleri oluşturur. Bu ölüm kalım savaşını kazanmamızı sağlayan mücadele ve savaşlar, 1921 ve 1922 seneleri içinde olan İnönü, Sakarya ve Büyük Taarruz gibi önemli savaşlardır. Bu dönem edebî açıdan da dikkat çekici bir dönemdir. II. Meşrutiyetin ilanıyla başlayan dönemde milliyetçilik, halkçllık ve dilde sadeleşme akımlarının da etkisiyle Halk Edebiyatı üzerindeki çalışmalar yoğunluk kazanır. Batı'da yapılan araştırmalar da dönemin aydınlarının bakışları$\mathrm{n} ı$ bu alana çevirmesini sağlar. Macar folklor bilgini Ignacz Kunos'un İstanbul'a gelmesi ilgiyi artıran sebeplerden biri olur. 1913 yılında Ziya Gökalp, Rıza Tevfik ve Köprülüzâde Mehmet Fuat'ın Halk Edebiyatı alanındaki araştırma ve yazıları görülür.
\end{abstract}

Anahtar sözcükler: milli mücadele, halk edebiyatı, destan, türkü, folklor

1 Doç. Dr., İstanbul Kültür Üniversitesi, Türk Dili ve Edebiyatı Bölümü. h.gulsen@iku.edu.tr 


\begin{abstract}
In the period of the National Struggle that started with the 1918 Mondros Armistice Agreement and continued until the end of 1922, the Turkish nation dives into a life and death struggle. We lose the first world war we have joined with the Alliance nations. Our lands are occupied by the Mondros Armistice Agreement signed on 30 October 1918 and the Sevres Agreement dated 10 August 1920. 1919 and 1920 constitute preparation phase of our National Struggle. The struggles and battles that led us to win this life - and - death battle are important battles such as İnönü, Sakarya and the Great Offensive that took place in 1921 and 1922. This period is also a remarkable period from a literary perspective. Nationalism, populism and the simplification of language in the period which started with the proclamation of the $2^{\text {nd }}$ constitutional monarchy intensify within this period.. Researches in the West also allow the intellectuals of the period to turn their interest into this field. The Hungarian folklore scholar, came to Istanbul and became one of the reasons that increased interest. In the year 1913, Ziya Gökalp, Rıza Tevfik and Köprülüzâde Mehmet Fuat's researches and writings in the field of folk literature emerge.
\end{abstract}

Keywords: war of independence, folk literature, saga, folk song, folklore

\title{
Giriş
}

Bu makalede, Millî Mücadele döneminde, Halk Edebiyatı alanında meydana gelen çalışmalar ve edebî tartışmalar ele alınmıştır. Millî bir mücadele verilirken sanatkârlarımızın sığındığı tek kaynak kendi kimlikleri ve kendi kaynakları olmuştur. Bu dönemde aydınlarımızın kendine dönmesi Halk Edebiyatı çalışmalarını da hızlandırmıştır.

30 Ekim 1918 tarihinde Mondros Mütarekesi’yle başlayan ve 1922 y1lı sonuna kadar devam eden Millî Mücadele döneminde Türk milleti bir ölüm kalım mücadelesi verir. I. Dünya savaşı kaybedilmiştir. Mondros Mütarekesi ve 10 Ağustos 1920 tarihli Sevres Muâhedesi ile işgal başlar. Bu dönem edebî açıdan dikkat çekici bir dönemdir. Halk Edebiyatı üzerindeki çalışmalar bu dönemde yoğunluk kazanır. Batı'da yapılan araştırmalar aydınlarının bakışlarını bu alana çevirir. Macar Türkolog Ignacz Kunos İstanbul'a gelir. 1913 yılında Ziya Gökalp, Rıza Tevfik ve Köprülüzâde Mehmet Fuat Halk Edebiyatı alanında yaptığı araştırma ve yazılarla dikkat çeker.

\section{Millî mücadele döneminde halk edebiyatı çalışmaları:}

Millî Mücadele Dönemi Edebiyatında Halk Edebiyatı çalışmaları büyük bir önem taşımaktadır. Nitekim Kırım Mecmuası yazarlarından olan Z. N., Halk Edebiyatını bir milletin en kıymetli ve en dikkat çekici değerlerinden biri görür. Onu millî örf ve adetlerin, millî dinin kısacası millî ruhun sadık bir aynası veya koruyucusu olarak tanımlar (Z.N. 1919: 379). Görüldüğü gibi 20. Yüzyılın ilk yarısında Millî edebiyat anlayışı çerçevesinde, Halk Edebiyatına gereken önem daha çok verilmeye başlanmıştır.

$\mathrm{Bu}$ dönemde Yeni Mecmua, Şair Mecmuası gibi devrin beğenilen dergilerinde makaleler görülür. Örneğin Yeni Mecmua "Halk Edebiyatından Numûneler" üst başlığıyla bu edebi- 
yattan örnekler sunar. Dergi, Halk edebiyatı için şöyle bir değerlendirmede bulunur: "Bizim eski şairler, padişahların, vezirlerin saraylarında, medrese köşelerinde Arap ve Acem taklidi musanna gazeller, kasideler yazarken, medrese tahsilini görmemiş bütün bir halk kitlesi, bütün bir âlem, kendi aralarından çıkan saz şairlerinin ruhlarının âlem-i ihtiyacına tekabül eden eserleriyle asırlarca yaşadı” ( 1918: 96).

Şair Mecmuası da, “Anadolu Türküleri” başlığıyla türküler yayımlar. Daha ilk yazıda Doktor Frederick Geise isminde bir Alman araştırmacıdan bahsedilir. Bu araştırıcının Anadolu'yu dolaşarak derlediği türküleri 126 sayfalık bir eser halinde yayımladığı haber verilmektedir. "Anatolischen Türkisch” ismindeki kitapta yer alan manzum parçaların şeklen bozuk olduğunu belirten yazar, vezin ve kafiyelerin düzgün, ahenkli giderken birdenbire k1rıldığını, ancak eserin saf ve çok samimî olduğunu ifade eder. Ona göre: "Gözümüzü benliğimize çevirerek kendi duygularımızı terennüm etmek istediğimiz bu devirde hâricî tesirlerden uzak kalmış olan bu kalp nağmelerinin çok kıymeti vardır” (1919: 54).

“Anadolu Türküleri” başlıklı ikinci yazıda da, şairlerimizin kiminin Arap, kiminin de Acemi örnek aldıkları, oysa millî bir edebiyata can vermek için çalışan kalemlere en çok rehberliği halk türkülerinin yapacağı ifade edilir (1919: 122,123).

Yine Şair Mecmuasında, edebiyatla uğraşanların, Fuzulîleri, Nedîmleri çok iyi bildikleri, fakat kış günlerinde, mangal başlarında okunan bazı divan ve masalların, düne kadar kıymet verilmeyen büyük bir kitlenin, zevklerinden bize haber veren önemli kaynaklar olduğu belirtilmektedir. Âşık Kerem'in bunların en meşhurlarından olduğu vurgulanarak, divanından alınmış bir örnekle dünkü ve bugünkü edebiyatımıza oranla ne kadar samimî olduğu söylenir (1919 : 173).

Ahmet Cevdet, İkdam Gazetesi’nde Necip Asım'a hitaben “Halk Edebiyatı” başlıklı bir yazı yazar. Bu yazıda İkdam’ın Halk Edebiyatına verdiği önemi de şu sözlerle açıklığa kavuşturur: “... Halk Edebiyatı meselesi bizim için pek mühim, pek ciddi, pek hayati meselelerdendir.” Bu önemli meselede Ahmet Cevdet, önce Halk Edebiyatının ne demek olduğunu tanımlamakla işe başlar: "Halk Edebiyatı demek halkın söylediği ve anlayacağı dilde, manzum ve mensur söz söylemek demektir." Ahmet Cevdet, bilgili insanların millî varlığının, millî kültürünün esaslarını araştırmamasının milletimiz için büyük bir talihsizlik olduğunu, ancak bu konuda yorulmayı göze almış olurlarsa istedikleri ilerlemenin sebep ve tesirlerini anlayacaklarını ve kendi milletlerinin ihtiyacını da takdir edeceklerini vurgular (Ahmet Cev$\operatorname{det} 1921: 1)$.

$\mathrm{Bu}$ dönemde folklor çalışmaları da başlar. Süleyman Şevket, İngilizce olarak kelimenin sözlük anlamını verir. "Folk - halk", "lore - ilm” anlamına gelmektedir. Bu kelimenin bizde karşılığı henüz bulunmamıştır. "Hikmet-i avam” tabiri vardır ancak kullanılmamaktadır. Yazar, yarın belki “halkiyat” denebileceğini ancak asıl önemli olan şeyin kelimenin manası olduğunu söyler. Folklor ürünleri halkın gelenek ve görenekleri, masallar, rivayetler, atasözleri, halk oyunları halk arasında yaşayan söylenen şeylerdir. Yazara göre bunların yazılıp yayımlanması tarihe, etnografyaya, dile değerli bir hizmet olacaktır. Folklor ilmî kavimlerin kardeşliğini güçlendirir. Ortak vicdanların, ortak özelliklerini, halk içinde kültürün çeşitli derecelerini gösterir. Asıl ruhî çehrenin hatlarını çizer. Süleyman Şevket, dilimizin Avrupa'nın doğusunda, Asya'nın ortasında konuşulduğunu, sözlüğümüzü, tarih ve edebiyatımızı yazma- 
ya şiddetle ihtiyacımız olduğunu, yetişecek yazarları beklediğimizi, şimdilik sadece belge toplayarak hazırlanmamız gerektiğini söyleyerek sözlerine son verir (Süleyman Şevket 1922: $22-24)$.

Bu dönemde destanlar üzerinde yapılan çalışma ve tartışmalar göz doldurur. Bilindiği gibi destan, Âşık edebiyatında bir nazım şeklinin de adıdır. Kelimenin aslı Farsça "dâstân"dır. Batı dillerinde bunun karşılığı olarak, Grekçe'de şairlerin saz eşliğinde söyledikleri şiirlere verilen "epos" adından türetilen épopée” (epopoeia) kullanılır. Destan, daha çok yaratılış, toplum vicdanında iz bırakan savaşlar, bir şahıs veya bir milletin kahramanlıkları ve tabiî âfetler, hikâye dışından katılan öğüt, kıssa, masal ve epik karakterli biyografik bilgilerle zenginleştirilerek genellikle anlatıma dayalı manzumeler şeklinde destana dönüştürülür.

Türk edebiyatında destan kelimesini XIX. yüzyılın sonu ile XX. yüzyılın başından itibaren Rıza Nur, M. Fuat Köprülü ve Zeki Velidi Togan Türkoloji alanındaki çalışmalarında "légende” ( efsane ) veya "épopée" karşılığında kullanmaya başlarlar. Böylece destan kavramı yeni bir mahiyet kazanarak Türklerin Müslüman olmadan önceki tarih, dil ve edebiyatının incelenmesinde bir çıkış noktası olur. Schiefner, Radloff ve Potanin gibi bilginlerin araştırmaları Türklerin ilk destan dönemlerini aydınlatır. Ziya Gökalp’ın “Türk Töresi” (İstanbul: 1923 ) ve "Türk Medeniyeti Tarihi" (İstanbul 1925) adlı eserlerinde menkıbe ve ustûre kelimelerini kullanmasına rağmen destan épopée karşılığı olarak yaygınlık kazanır; Mehmet Fuat Köprülü ise "millî destan” sözünü tercih eder (Yetiş, 1994 : 202 ).

Destan kelimesini Divan şairleri de kullanmışlar, aruz vezniyle yazdıkları manzum hikâyelere destan veya dâstân demişlerdir. Mesela Şeyh Galip "Hüsn ü Aşk” adlı mesnevisinde tasvir ettiği "Benî Muhabbet” kabilesinin durumunu "Agaz-ı Dâstân” bölümünde anlatır.

Halk şiirinde destan, dörtlük şeklinde genellikle $6+5=11^{\prime}$ 'li hece vezniyle tertip edilir. Halk şairleri savaşlara, meşhur adamlara büyük hâdiselere özel ve gülünç olaylara dair destanlar yazmışlardır.

Millî Mücadele dönemi edebiyatında eski Türk destanları hakkında yazılar yazılır ve bunlar tanıtılır. Şair mecmuasında "Türk Esâtiri” başlığı altında; "Altay Türklerinde Yaratılış Ustûresi, Altay Türklerinde Insanın Doğuşu ve Ölüşü, Altay Türklerince Dünyanın Sonu, Yakut Türklerinde İlahların Muâşakası” gibi makaleler yayımlanır.

Şair Mecmuasında yer alan "Altay Türklerinde Yaratılış Ustûresi”" adlı ilk makalede, henüz yer ve gök yaratılmamışken, boşlukların yerinde sadece suyun ve tanrı Kara Han'ın oldu$\breve{g}$ u, tanrı Kara Han'ın hem gören ve hem de görünen canlılar yaratmaya karar verdiği anlatılır.

İlk önce kendisine benzeyen bir canlı yaratan Kara Han, ona "Kişi” adını verir. Uçma yeteneği olan Kişi, bir zaman sonra bahtiyarlık içinde yaşamaktan sıkılır ve daha yükseklere uçmak ister. En gizli şeyleri gören Kara Han, Kişi ’nin düşüncesini sezer ve ondan uçma yeteneğini alır. Suyun içine batan Kişi af diler. Kara Han ona, suyun dibine inmesini, oradan katılaşmış sudan bir parça getirmesini ister. Kişi suyun dibine dalar, buradan çıkardığı buzu getirir ama bu buzun bir parçasını da ağzına atar. Çünkü kendi kendine gizli bir ada yapmak istemektedir. Kara Han, buza toprak ol! deyince buz toprak olur. Bu arada Kişi'nin ağzındaki buz da toprak olup şişince Kara Han Kişi’ye “tükür!” der. Bu tükürükten de dağlar, tepeler meydana gelir. Kişi’’nin gizli iş yapmak istemesi sonucunda yeryüzü girintili ve çıkıntılı bir 
görünüşte olur. Bu ikinci günahtan dolayı Kara Han, Kişi ’ye “Erlik” adını verir. Onu yeryüzünden kovar. Kara Han, dünyayı şenlendirmek için yeraltından dokuz dallı bir ağaç bitirir ve bu ağacın dalları altında insanlar yaratır. Türklerin bu yaratılmış dokuz kişiye yani atalara büyük saygısı vardır. Erlik, yeryüzünün bu yeni sahiplerinin idaresini Kara Han'dan ister. Kara Han, bu isteği geri çevirir. Erlik, insanları büyücülük kuvvetiyle istediği gibi kandırır ve kendi tarafına çeker. Kara Han bu insanlara kızar, yeryüzünü onlara bırakır, Erlik’i de yeraltındaki karanlık göğün üçüncü katına gönderir. İşte insanlar bu şekilde, doğruyu kendi kendilerine bulmaya mahkum olurlar. Geçimlerini kendileri kazanmak zorunda kalırlar. Erlik'se boş durmadan insanları kandırmaya devam eder. Kara Han, göğü yaratır. On yedinci katı kendine ayırır. Kara Han'dan üç tanrı meydana gelir. Birincisi iyilik tanrısı olan Bay Ülgen'dir. Onu cennete amir tayin eder. Erlik, cehennemin, Bay Ülgen de cennetin tanrısı olur (1919: 67, 68).

“Altay Türklerinde Insanın Doğuşu ve Ölüşü” adlı makalede ise insanın dünyaya gelişi üzerinde durulur. Bir insan dünyaya geleceği zaman, Bay- Ülgen oğlu Yayık’1 bu işe görevli kılar. Cennetteki analar torunlarının iyi insanlar olmasını istediklerinden, Yayık Yayuçı ’ya, çocuğun ruhunu Süt Gölü'nden almasını ister. Yayuçı, Süt Gölü’nden bir damla alır. Bu damladan çocuğun ruhunu yaratarak dünyaya gelmesini bekler. Erlik de dünyaya bir insan gelmekte olduğunu haber alarak, o da bir Körmös gönderir. Yayuçı, hamile kadının sevaplarını göz önüne alırken, Körmös de, günahlarını sayarak kadına sancılar çektirir. Çocuk doğduktan sonra Yayuçı sağ omzunda, Körmös de sol omzunda kalır. Bu insanın bütün hayatı boyunca hareketlerini kontrol eder. Altay Türkleri, hastalıkların Erlik, sıhhatin ise Bay-Ülgen tarafından geldiğine inanırlar. Herkes yaptığı iyiliklerin ve kötülüklerin karşılığını bulur. İslamiyetten önce, Türklerin tepelerinde birer saç örgüsü vardır. Çünkü başında saç örgüsü bulunmayan bir insanın ruhu katrandan çıkarılamaz, sonsuza kadar cehennem kazanında kalır. Atalar hiçbir zaman yeryüzündeki torunlarıyla, cehennemdeki evlatlarını unutmazlar (1919: $82,83)$.

“Altay Türklerince Dünyanın Sonu”, adlı makalede ise İslamiyetten önceki Altay Türklerinin dünyanın sonu hakkındaki inanışları anlatılır. Bir gün tanrı Kara Han, gögün on yedinci katında tahtında otururken, Bay- Ülgen'in iki oğlu, Yayık ile May- Tere huzura gelirler. MayTere, insanların artık sözlerine kulak vermediklerini, gökteki tanrıları unutup, yeryüzünde dağa, taşa, göllere tapmaya başladıklarını söyleyip durumu Kara Han’a bildirir. Kara Han, İyiliği, barışı isteyen Bay- Ülgen'in sonsuz istirahatine çekilmesini ister. İnsanların kozlarını Erlik Han'la paylaşmasını ister. Erlik de Körmös 'lere, İnaslara, Yaman Uzatlara yeryüzünün yerle bir edilmesi emrini verir. Altay Türklerine göre kıyamet günü bu şekilde gelecektir (1919: 98, 99).

“Yakut Türklerinde İlahların Muâşakası” adlı makalede de, gökyüzünün en büyük tanrısı Arıt Toyon, dünyaya güzellik saçmak görevini kızı Güneş Hanım ’a bırakır. Yeryüzünün tanrısı Ulu Toyon, Güneş Hanım'a âşık olur. Babası Seçen’e yalvararak kızı istetir. Arıt Toyon kızının istediği nişan hediyelerinin dalga ve serap olduğunu söyler. Ulu Toyon, kurdu dalgayı, kargayı da serabı getirmesi için görevlendirir. Ancak her ikisi de hediyeleri getiremez, Ulu Toyon Güneş Hanım'ı alamaz ama Güneş Hanım bir gün bir erkek çocuk doğurur adını Gün Han koyarlar (1919:114). 
Millî Mücadele döneminde savaş cephelerinde bir varoluş destanı yazılırken, bir yandan da destan hakkında çeşitli değerlendirmeler ve tartışmalar yapılmıştır.

$\mathrm{Bu}$ değerlendirmelerden birini yapan Yusuf Ziya, destan türünün her milletin edebiyatında önemli bir yer işgal ettiğini düşünür. Destanı bir tür olarak değerlendirir, bu türde yazılmış eserlerin kalitesiz olduğunu da sözlerine ekler. Ona göre: “destanlarda millî rüyalardan, geleneksel hislerden, mahallî zevklerden alınmış açık yansımalar” yaşamaktadır. Ancak bizde meydana getirilmiş son eserler ne yazık ki uydurma eserlerdir (Yusuf Ziya, 1919:161).

Yakup Kadri ise, kimi milletlerin destanını mürekkeple kağıt üzerine, kimisinin de kendi kanıyla kendi toprağına yazdığını söyler. Söze ve gösterişe önem vermeyen Türk milletinin, yüzyıllarca "İliada" ya konu teşkil edecek kadar büyük olan geçmişinden bir destan çıkarmay1 düşünemediğini sözlerine ekler. Bunun nedenini de Türk'ün yaptığı işin, daima söylediği sözden daha büyük olmasına bağlar (Yakup Kadri, 1921:2).

$\mathrm{Bu}$ dönem edebiyatında destan türünün asrî olup olmadığına ve millî bir destanımız olup olmadığına ilişkin birtakım tartışmalar meydana gelir. Tartışmayı Ali Canip'in “Epope Nedir?" başlıklı yazısı başlatır. Ali Canip yazısına, Epopée 'nin eski Yunancasının "epopila” olduğunu, "Epos"un şiir, "Piin”in ise yapmak anlamına geldiğini, epopenin de şiir yapmak, şiir söylemek olduğunu söyleyerek başlar. Voltaire, epopeyi kahramanca maceraların manzum hikâyesi diye tarif etmiştir. Bu çeşit eserler bir millete ya da insaniyete ait başarıları, felaketleri, maceraları gösteren eserlerdir.18.yy edebiyatçılarından François Marmontel epopeyi ferdî zekânın bir ürünü gibi kabul etmiş, konunun seçimine, planına, manzumenin vasıflarına dair uzun uzadıya kurallar koymuştur. Bu anlayışı yanlış bulan Ali Canip, epopenin konularını, o konulardaki kahramanları, hatta kahramanların maceralarını milletlerin ma'şerî muhayyilelerinin yani halkın zekâsının yarattığını belirtir. Halkın zekâsının epope konularını nasıl yarattığını anlatmak için de Ribot'nun "Yaratıcı Muhayyile Üzerine Tetkik" adlı eserinden yararlanır. Ona göre, edebiyatçılar epopede dört esas unsur ararlar: "Olay, kişiler, şekil, üslûp." Yine Ali Canip'e göre edebiyatçılar epope adına uygun bir eseri meydana getirmek için şu şartları sayarlar: Büyük bir konunun bulunmasl, dil ile hayal gücünün çok gelişmiş olması, birtakım seçkin şairlerin olması. Yazarımıza göre, 20. yüzyılın edebiyatı tamamıyla aklın etkisi altındadır. Bugünün epopeleri romanlardır. Ali Canip tartışmayı fitilleyen şu soruyu sorar: "Bizim epopemiz var mı? Son teşkilat ile yavaş yavaş Türklerin de bir esatiriyyâtı olduğu meydana çıkıyor. Halkımızın birçok efsaneleri de var. Fakat eski şairlerimizden hiçbiri müdahaleden kurtularak bir epope yazmamıştır. Emin Beyefendi'nin son senelerde yazdıkları bazı manzumelere epope namı veriliyor. Bu büsbütün yanlıştır. ... Son söz millî epopemiz yoktur. Epope asrî bir nevi olmadığı için artık yazılamaz da” (Ali Canip, 1918).

Ali Canip'in bu sözlerine cevap Faruk Nafiz'den gelir. Faruk Nafiz'e göre, Ziya Gökalp'ın fikirlerini anlayamamış olan Ali Canip, bir gün ansızın Yeni Mecmua’da destanî şiirlerin artık yazılamayacağını iddia etmiştir. Bu şairimizin ifadesine göre, “dünyanın en gülünç, en kötü olayı"dır. "Çünkü Klasik edebiyatta destanın belirli bir tabiatı ve belirli kuralları, yirmi dört bent üzerine kurulmuş belirli bir şekli vardır. Bu da asıl örneği olan İliada' dan çıkmaktadır. ” Şairimiz, destanın ölmediğini, tam tersine modern edebiyatta dirildiğini düşünür. Aynı 
zamanda Ali Canip gibi düşünen bir şair veya yazarın bilgi ve tenkit dünyasında bir yer alamayacağı gibi, edebiyatta da olumlu ve etkili bir şahsiyetinin olamayacağını belirtir (Faruk Nafiz, 1919:131-133).

Görüldüğü gibi Faruk Nafiz, Ali Canip’ten farklı düşünmektedir. Ona göre epope yani destan ölmemiş, tam tersine modern edebiyatta yeniden vücut bulmuştur. Tartışma bu şekilde başlamışken Ali Canip, Ribot'nun destan ve diğer edebî türlerin tarihi gelişimi hakkındaki fikirleri üzerinde durur. O da, Ribot gibi mitolojinin milletlerin ortak hayal gücünden doğduğuna inanır. Destanlar ise mitolojinin lüks bölümünden meydana gelmektedir. Destanlarda ilâhî şahsiyetler yer alır. Yavaş yavaş ilâhî karakterler silinir. Efsâne insanî hayatın şartlarına yaklaşarak roman şekline girer. Sonuçta bugünkü realist roman meydana gelir.

Ali Canib’e göre, şimdiki edebiyat medeniyetin değişen şartlarına uymuş, şeklini değiştirmiş bir mitolojiden ibarettir. Ali Canip, iki şeyin unutulmamasını ister. Birincisi destanın konusunun şairin kendi zekâsından çıktığıdır. Troi Savaşı Homeros'dan önce Yunanlılar'ın, İran'la Turan'ın mücadelesi Firdevsi'den önce Acemler'in vicdanında yaşamaktadır. İkinci olarak unutulmaması gereken Homeros yahut Firdevsi'nin zekâlarıyla yazdıkları eserde esas özellik olan “merveilleux - harika"nın samimî olarak birleşimidir. Ali Canip, Ribot'nun fikirlerine katılarak bugünün destanlarının romanlar olduğunu söyler. Eski destanların zevkle okunduğunu, ancak onları taklit ederek yeniden yazmanın doğru olmayacağını tekrarlar. Ali Canip, destan ile "poem épik” yani epik şiirin başka şeyler olduğunu vurgular. Yeni şairler, herhangi bir kahramanlığı idealleştirerek bir eser yazabilirler fakat bu destan olamaz. Ali Canip, Tevfik Fikret'in “Hasan'ın Gazası” adlı şiirini örnek olarak verir. Terbiye ve ilim alanında itirazları olanlarla tartışmaya hazır olduğunu söyleyerek sözlerine son verir (Ali Canip, 1919: 58, 59).

Köprülüzâde Mehmet Fuat, “Epope Meselesi ” adlı yazısıyla Ali Canip’in Yeni Mecmua' da ve Büyük Mecmua'da yayımlanmış epope hakkındaki yazılarına cevap verir. Böylece Faruk Nafiz'den sonra tartışmaya katılır. Köprülüzâde Mehmet Fuat'a göre, Türk destanı diğer millî destanlardan daha zengin ve daha şairâne bir değere sahiptir. Millî Türk destanının oluşmasının Millî edebiyatın gelişip, millîleşmesine katkısı olacaktır. Köprülüzâde Mehmet Fuat, yarınki Türk edebiyatının sağlam esaslara dayanabilmesi için millî zevkin yabancı milletlerin zevkinden ayrılması gerektiğini, ancak bunun da millî destanın meydana getirilmesinden sonra doğacağını söyler. Yazarımız, Alman ve Rus romantiklerinin yaptığı gibi millî sanatın unsurlarını millî destan kalıntılarından alıp, millî zevkimize göre o unsurları terkip ederek millî olduğu kadar asrî bir edebiyat meydana getirebileceğimize inanır. O, Millî edebiyat hareketinin Türk romantizmine doğru bir cereyan şeklinde olmasını istemiş, bunun için geçmişe, halka, folklora, halk vezin ve diline, halk zevkine, bir kelime ile millî destana gidilmesini desteklemiştir. Köprülüzâde Mehmet Fuat, Ali Canip'in “Epope Nedir?” makalesinde Ribot'dan çıkardığı sonuçlarla, Millî Edebiyat hakkındaki temel ilkelere hücum ettiğini düşünür. Yazarımız, epopenin ferdin hayal gücünün keyfine göre meydana gelmediğini, bir defa oluşmuş millî destan parçalarının toplanıp, terkip edilmesinin mümkün olduğunu belirtir. Bu noktada Ali Canip’ten ayrıldığını gördüğümüz Köprülüzâde Mehmet Fuat, Alman romantizmini örnek olarak vererek, "Nibelungenlied" ve buna benzer eski Alman destanlarının sadece edebiyatta değil, müzik, resim gibi alanlarda gösterdiği etkiden bahseder. Yalnız bir 
kez meydana gelmiş destanın en yeni ve en asrî sanatkârlar tarafından başarıyla kullanılabileceğini, Firdevsî gibi sanatçılar tarafından toplanabileceğini belirten Köprülüzâde Mehmet Fuat, bir sanatkâr tarafından yazılmış olan her destanın örneğin "Şehname"nin bir "epik şiir" olduğunu ancak her epik şiirin mutlaka halkın ortak ürünü olan epope sayılamayacağını da sözlerine ekler. Ona göre bir Türk destanı ancak Firdevsî kudretinde ve mizacında bir şair tarafından meydana getirilebilir (Köprülüzade Mehmet Fuat, 1919:68, 69).

Millî Türk destanının oluşmasının Millî edebiyatın gelişmesi ve millîleşmesine katkısı olacağını düşünen Köprülüzâde, millî destan parçalarının toplanıp bir araya getirilmesinin mümkün olduğuna inanır. Köprülüzâde, Ali Canip'in Ribot'dan çıkardığı sonuçlarla da Millî edebiyatın temel ilkelerine saldırdığını düşünmektedir. Millî bir destanın Firdevsî ayarında bir edebiyatçı tarafından yazılabileceğine inanır.

Ali Canip, bu yazıdan tam bir hafta sonra, Büyük Mecmua' da “Yine Epopeye Dair” makalesiyle Köprülüzâde Mehmet Fuat'ın tenkitlerine cevap verir. Yazarımız, destanın modern bir tür olmadığını, millî destanımızın bulunmadığını, bundan sonra da yazılamayacağını Ribot'nun fikirlerini göz önüne alarak tekrar eder. Ona göre, destan modern bir tür değildir, şairler eski destanları taklit ederek bir destan oluşturamaz fakat Köprülüzâde Mehmet Fuat'ın dediği gibi millî destan varsa toplanabilir. Bu yeniden destan yazmak manasına gelmez. Destanın modern olmadığını söylemek eski destanlardan ilham alınamayacağı anlamını da taşımaz. 17. yüzyılda Racine bunu başarabilmiştir ancak bu eserlere destan değil trajedi denmektedir. Ali Canip'e göre bir Türkçü yazarın, yalnız edebî değil, sosyal, siyasî, iktisadî yoksulluktan bahsetmesi onun milliyet aleyhinde olduğunu göstermez. "Hakikat zararlı değildir. Millî destanımız yoktur” (Ali Canip, 1919:84,85). Ali Canip bu yazısıyla tartışmaya son noktayı koyar. "Millî bir destanımız ne yazık ki yoktur!"

\section{Sonuç:}

Millî Mücadele Dönemi olarak adlandırdığımız 1918 -1923 tarihleri arasında Türk milleti bir ölüm kalım mücadelesi verir. Bu mücadelede kendi yüreğinden aldığı güçle, kendi özgürlüğünü kazanacaktır. Kendine döndüğü bu dönemde Halk Edebiyatı ürünleri en önemli kaynak olarak ona yol gösterir. Bu nedenle Halk Edebiyatı ürünlerine, Millî Mücadele döneminde daha çok önem verilir. Bu dönemde Halk Edebiyatı üzerine yapılan çalışmalar devrin gazete ve dergilerince de destek görür. Türküler ve masallar derlenir ve örnekleri dergilerde yayımlanır. Folklor çalışmaları bu dönemde başlar. Destanlar, türküler, masallar çeşitli gazete ve dergilerde tanıtılır ve önemlerinden bahsedilir. Halk Edebiyatının bu ürünleri büyük küçük herkesin zevk aldığı türler olarak dikkat çeker.

Millî Mücadele dönemi edebiyatında, Halk edebiyatı ürünleri içinde destanlara diğer türlerden daha çok önem verilir. Destanlar tanıtılır. Örneğin Altay Türklerinde Yaradılış Ustûresi”, “Altay Türklerinde İnsanın Doğuşu ve Ölüşü”, “Altay Türklerinde Dünyanın Sonu”, "Yakut Türklerinde İlâhların Muâşakası” gibi yazı başlıkları dikkat çeker.

Bu dönemde Halk edebiyatı üzerine yapılan tartışmalar yok denecek kadar azdır. Millî bir destanımızın olup olmadığına dair yapılan bir tartışma ise dikkat çekicidir. Ali Canip'in, “Millî epopemiz yoktur. Zirâ epope asrî bir tür olmadığı için artık yazılamaz da” sözlerine 
karşılık, Faruk Nafiz, destanın ölmediğini, tam tersine modern edebiyatta dirildiğini söyler. Tartışmaya katılan Köprülüzâde Mehmet Fuat ise, Millî Türk destanının oluşmasının Millî edebiyatın gelişmesi ve millîleşmesine katkısı olacağını belirtir. Millî destan parçalarının toplanıp bir araya getirilmesinin mümkün olduğuna inanır. Köprülüzâde Mehmet Fuat, Ali Canip'in, Ribot'dan çıkardığı sonuçlarla millî bir edebiyatın temel ilkelerine saldırdığını düşünür. Millî bir destanın ancak Firdevsi ayarında bir edebiyatçı tarafından yazılabileceğine inanır.

Sonuç olarak diyebiliriz ki, Halk Edebiyatı ürünleri ve özellikle destanlar bizim asıl kaynaklarımız olarak bu dönemde tekrar eski değerini kazanmış, Türk okuruna kendisini tanıma yolunda büyük bir hizmet vermiştir. Özgürlüğümüzü kazanma yolunda verdiğimiz mücadele, edebî örneklerle sanatkârlar tarafından da desteklenmiştir.

\section{Notlar:}

Şair Mecmuasında Destan türüyle ilgili yayımlanan makaleler sırasıyla şunlardır: Altay Türklerinde Yaradılış Ustûresi, Şair, nr.5, 9 Kanunısâni 1919; Altay Türklerinde İnsanın Doğuşu ve Ölüşü, Şair, nr.6, 16 Kanunısâni 1919; Altay Türklerinde Dünyanın Sonu, Şair, nr.7, 23 Kanunısâni 1919; Yakut Türklerinde İlâhların Muâşakası, Şair, nr.7, 23 Kanunısâni 1919.

\section{Kaynaklar}

Ahmet Cevdet (1921). Halk edebiyatı. İkdam, nr.8713, 17 Haziran.

Ali Canip (1918). Epope nedir? Yeni Местиа, nr. 62, 26 Eylül.

Ali Canip (1919). Epope asrî bir nevi midir? Büyük Местиа, nr.4, 27 Mart.

Ali Canip (1919). Yine epopeye dâir. Büyük Мecmua, nr.6, 24 Nisan.

Anonim- (1919). Altay Türklerinde yaradılış ustûresi. Şair, nr.5, 9 Kanunısâni..

Anonim - (1919). Altay Türklerinde insanın doğuşu ve ölüşü. Şair, nr.6, 16 Kanunısâni.

Anonim - (1919). Altay Türklerinde dünyanın sonu. Şair, nr.7, 23 Kanunısâni.

Anonim - (1919). Anadolu türküleri. Şair, nr.4, 2 Kanunısâni.

Anonim - (1919). Anadolu türküleri. Şair, nr.7, 23 Kanunısâni.

Anonim - (1919). Âşık Kerem. Şair, nr.11, 20 Şubat.

Anonim - (1918). Halk edebiyatından numûneler. Yeni Мecmua, nr.31, 8 Şubat.

Anonim - (1919). Yakut Türklerinde ilâhların muâşakası. Şair, nr.7, 23 Kanunısâni.

Faruk Nafiz (1919). Lüzumlu bir teşhir. Şair Nedim, nr.9, 13 Mart.

Köprülüzâde Mehmet Fuat (1919). Epope meselesi. Büyük Мecmua, nr.5, 9 Nisan.

Süleyman Şevket (1922). Folklor hakkında bir teşebbüs. Muallim Mecmuası, S. 2, 22 Teşrinievvel.

Yakup Kadri (1921). Küçük bir risale münasebetiyle. İkdam, nr.8580, 30 Ocak.

Yetiş, K. (1994). Destan. Diyanet İslam Ansiklopedisi. C.9, İstanbul, s.202.

Yusuf Ziya (1919). Tehlike. Şair, nr.11, 20 Şubat.

Z. N. (1919). Halk edebiyatının ehemmiyeti hakkında. Kırım, nr.22. 